\title{
Neglected Physical Evidence during Crime Scene Investigation
}

\author{
Nataraja Moorthy T* \\ Faculty of Health and Life Sciences, Management and Science University, Malaysia \\ *Corresponding author: Nataraja Moorthy T, Faculty of Health and Life Sciences, Management and Science University, Shah Alam, Malaysia

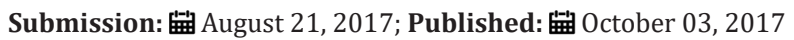

\section{Opinion}

Forensic is a fascinating term used not only by the forensic personnel but also by non-forensic personnel for various purposes. Many movies and dramas include forensic elements in their storylines which use forensic techniques contributing to the crime scene investigation and solve the mystery within hours. The gap between forensic science fiction and reality is far wide. The aspects of forensic fiction are different from real-life forensic investigation. Contrary to the way it is portrayed in popular media, crime scene investigation is not glamorous or accomplished in an easy manner [1].

"Wherever he steps, whatever he touches, whatever he leaves, even unconsciously, will serve as silent witness against him. Not only his fingerprints or his footprints, but his hair, the fibers from his clothing, the glass he breaks, the tool mark he leaves, the paint he scratches, the blood or semen he deposits or collects. Physical evidence cannot be wrong, it cannot perjure itself; it cannot be wholly absent, only its interpretation can err. Only human failure to find it, study and understand it can diminish its value [2]".

But some investigators underestimated or overlooked the evidences like fiber, hair and footprints in many incidents and neglected from the initial stage of investigation presumed that they are unimportant. But at the same time, these evidences gained important in high profile cases since the investigators are answerable to top level officials.

As a field criminalist, I observed one such physical evidence that is intentionally neglected by the investigator is footprint. Footprint is one of the most valuable, misunderstood and underutilized form of physical evidence. Even in some educational institutions, under impression evidence, footprint is not at all included in the forensic science syllabus, while insisting the importance of shoeprint or footwear print.

As a forensic practitioner, many mysterious crimes had been solved scientifically only through footprint in cases like house burglaries, homicides, suspicious deaths, firearm cases and so on. In a homicide investigation, feeble bloody footprints found in crime scene were the only physical evidence which turned the complainant into accused [3]. As an expert witness, my testimony on footprint was accepted by the honorable judge in the court and at length the case ended with convection. Similarly in a serial burglary cases, there were no witnesses to these cases but the presence of footprints and gait patterns showed inter se and indicated a team of 4 burglars struck as many as housing for more than one year. Without knowing their offence, the burglars were brought to police station under suspicious condition by night patrolling officers. Their finger prints and foot prints were collected for comparison analysis. The collected footprints of the suspects were found tallied with the crime scene footprints. The interesting feature is that these suspects were the first offenders and hence they were not recorded criminals. During the trial the honorable judges accepted the value of footprint evidence and finally the judge awarded imprisonment to the offenders [4-7].

Footprints are overlooked for the following reasons:

a. The lack of training and education in the proper searching, collection and preservation of the evidence

b. The evidence is undervalued or not understood

c. Not believing that the impressions can be found at the scene after people have walked over the scene

d. Incomplete searches of the crime scene

e. The impression has been intentionally destroyed Footprint and trails can indicate:

f. The number of persons involved

g. The age of a person-whether the person is child, young or old

h. Height of the person

i. Body weight the person

j. Gender of the person

k. The mode of gain-whether the person was standing, moving slowly, walking fast or running.

l. Whether the person was carrying some load 


\section{Footprint Research}

Currently many academicians are showing interest in footprint research and have been publishing their result findings in journals and conference proceedings. Footprints will give more information than fingerprints to the investigators. Footprints can show individual characteristics for person identification. A person cannot commit a crime without performing some activity in the crime scene. A good investigator is knowledgeable, presence of mind, patient, persistent and reads a lot about variety of subjects regardless of title, pay or rank.

\section{References}

1. Krishan K, Kanchan K, Passi N, John AD (2012) Heel-Ball (HB) index: Sexual dimorphism of a new index from foot dimensions. Journal of Forensic Sciences 57(1): 172-175.
2. Paul L K (1974) Criminal Investigation, Krieger Publishing Company, USA.

3. Robbins LM (1986) Estimating height and weight from size of footprints. J Forensic Sci 31(1): 143-152.

4. Nataraja Moorthy T, Rina HOB (2008) Gait Pattern Analysis in Crime Scene investigation. Tamilnadu Police Journal 2(3): 61-70.

5. Nataraja Moorthy T, Wan Nur Z, Mohamad S (2011) A study on footprints of Malaysian athletes and non-athletes for application during forensic comparison. Malaysian Journal of Forensic Sciences 2 (1): 29-35.

6. Nataraja Moorthy T, Ang YL, Saufee AS, Nik F (2014) Estimation of stature from footprint and foot outline measurements in Malaysian Chinese. Australian Journal of Forensic Sciences 46(2): 136-159.

7. Nataraja Moorthy T, Fatimah S (2015) Individualizing characteristics of footprints in Malaysian Malays for person identification in forensic perspective. Egyptian Journal of Forensic Sciences 5(1): 13-22. 